\title{
EFFECT OF THE MEMBRANE CHARACTERISTICS AND OPERATION MODES, IN THE FOULING OF ULTRAFILTRATION MEMBRANES BY NATURAL ORGANIC MATTER (NOM)
}

\author{
CESAR GARCÍA', EDUARDO ROGEL-HERNÁNDEZI, LUCÍA Z. FLORES-LÓPEZ², \\ HERIBERTO ESPINOZA-GÓMEZ ${ }^{1, *}$ \\ ${ }^{1}$ Facultad de Ciencias Químicas e Ingeniería, Universidad Autónoma de Baja California-Tijuana, Calzada Tecnológico 14418, CP 22340, \\ Del. Mesa de Otay, Tijuana, BC México. \\ ${ }^{2}$ Centro de Graduados e Investigación del Instituto Tecnológico de Tijuana, Blvd. Industrial s/n. Tijuana, B.C., México \\ (Received: March 10, 2011 - Accepted: November 23, 2011)
}

\begin{abstract}
Membrane fouling by natural organic matter (NOM) is a major problem in ultrafiltration (UF) water treatment. The objective of this study was to evaluate the effects of operations modes on natural organic matter fouling, rejection and flux decline during UF. A comparison of constant pressure and constant flux tests confirmed that modest constant flux provided the most beneficial conditions. As general observation hydrophilic membranes were less prone to NOM fouling.
\end{abstract}

Keywords: Natural organic matter, Ultrafiltration membrane; NOM; UF fouling

\section{INTRODUCTION}

In view of the requirement for increasing water quality, membrane processes gained attraction because of the enhanced purification that is possible with membrane technology. ${ }^{1}$ Membrane processes are often chose since these applications achieve high removals of constituents such as dissolved solids, organic carbon, inorganic ions, and regulated and unregulated organic compounds. $^{2}$

Cellulose-based membranes are the state-of-the-art for lowfouling membranes. However, their low chemical stability and relatively low surface porosity are the significant limitations. Therefore, surface modification of established commercial membranes, such as polypropylene, poly(ether) sulfones, and poly(vinyldiene fluorine), while preserving their chemical resistance and mechanical strength, is of great interest for producing lowfouling membranes. ${ }^{3}$ Various separation procedures have been employed for polymers: gel permeation chromatography, membrane filtration to fractionate polymers by their size (molecular weight), electrophoresis, and others. Specially designed online membrane filtration devices were recently tested on polydispersed substances, namely for aquatic humic substances. ${ }^{4}$

One serious problem faced by the membrane process is fouling; membrane fouling is an extremely complex phenomenon. According to Koros et al., ${ }^{5}$ fouling is the process resulting in loss of the performance of a membrane due to deposintion of suspended or dissolved substances on its pore. This occurs when rejected solids are not transported from the surface of the membrane back to the bulk stream. Fouling deteriorates the performance of all types of membrane costing the plants billion of dollars.

The problem of membrane fouling by natural organic matter (NOM) is commonly experienced in membrane filtration of natural waters for drinking water treatment. ${ }^{6,7}$ Fouling of UF membrane can be influenced by many different factors, especially by the properties of the solution phase, ${ }^{8}$ the properties of the membrane itself, ${ }^{9}$ Operating parameters, and the interaction of the molecules in solution with the membrane surface material, also tend to cause fouling. ${ }^{10,11}$

Membrane fouling can be classified on the basis fouling materials as: inorganic fouling, biofouling and organic fouling. ${ }^{12}$

Organic fouling is usually discussed in terms of adsorption of various organic materials on and in the membrane. Many studies suggested that natural organic matter (NOM) was the most important foulant. ${ }^{13-15}$

Natural organic matter (NOM) is naturally occurring and widely distributed throughout all aquatic environments containing surface water. The NOM is composed of a wide variety of chemical complex organic compounds. ${ }^{16}$

The presence of natural organic matter in water is associated with a number of problems and the formation of harmful by-products on chlorination process of water treatment. ${ }^{17-20}$ One particular group of contaminants that is present in water supplies and which has brought about concern in the water industry is humic substances.

Humic substances in aquatic environments which are considered to be the major fraction of NOM are refractory anionic macromolecules of low to moderate molecular weight. Humic substances contain both aromatic as well as aliphatic components with primary carboxylic and phenolic functional groups. As a result, humic substances are negatively charged in the $\mathrm{pH}$ range of natural waters. It has been reported that NF and UF membrane found to be effective in removal of NOM from water surface. ${ }^{1,15,21-27}$

The aim of this study was to investigate the effects of membrane properties and operating conditions on model parameters during flux decline in deadend UF of NOM, and to develop an empirical relationship among membrane operation conditions.

\section{Theoretical basis}

The more widely used technique for identifying fouling mechanism is by searching which of the model equations listed on Table 1, fits the experimental data. Mathematical models have been illustrated to explain permeate flux decline in dead-end operation during filtration. ${ }^{28,29}$ The mathematical models can be shown as follows (Ec.1)

$$
\frac{d J_{v}}{d t}=-k J_{v}\left(J_{v}\right)^{2-n}
$$

where $k$ is a rate constant of fouling coefficient, $J$ is the permeate flux, and $n$ is the dimensionless filtration constant: cake formation model $(n=0)$; intermediate blocking model $(n=1)$; pore constriction or standard blocking model $(n=1.5)$, and complete pore blocking $(n=2)$. For longer filtration times, there was a transition in the fouling mechanism from pore blocking to cake formation. This transition occurred first for the more permeable membrane, indicating that colloidal NOM penetrates more readily into the pores of this membrane and that the relative size of colloidal NOM and the membrane pore influences the rate of pore blocking. The results further suggest that the structure of the fouling layer is dependent on the operating pressure. ${ }^{30}$

\section{Materials and methods}

NOM was isolated from the Alamar River in Tijuana City, México as described elsewhere. ${ }^{25,} 31$ Poly(diallyl dimethylammonium chloride) with different average molecular weight were purchased from Aldrich.

The membranes used in this study were flat-disc ultrafiltration membranes from Milliphore PB (hydrophobic membrane) and PL (hydrophilic membrane) series (PBCC Biomax PES and PLGC Ultracel RC) with NWMCO of 5 and $10 \mathrm{kDa}$. 


\section{Filtration protocols}

The blended aqueous solutions were stirred for $30 \mathrm{~min}$ at $120 \mathrm{rpm}$, after that the feed solution was filtered through the membrane. All the experiments were carried out in a dead-end stirred batch cell (UF stirred cell $76 \mathrm{MM}$ from Millipore, total volume of $300 \mathrm{~mL}$ ), and membrane effective filtration area of $2.8274 \times 10^{-3} \mathrm{~m}^{2}$ (total membrane area of $4.18 \times 10^{-3} \mathrm{~m}^{2}$ ).

The cell was operated at a constant transmembrane pressure (TMP) of 100 $\mathrm{kPa}$, regulated with high purity nitrogen gas, and stirred at $300 \mathrm{rpm}$. For constant flux experiments, the feed reservoir was pressurized to $20 \mathrm{kPa}$ with nitrogen gas and a peristaltic pump was connected to the permeate line to control the flux (Fig. 1). The $\mathrm{pH}$ of solutions was adjusted by $0.1 \mathrm{~N}$ hydrochloric acid or sodium hydroxide.

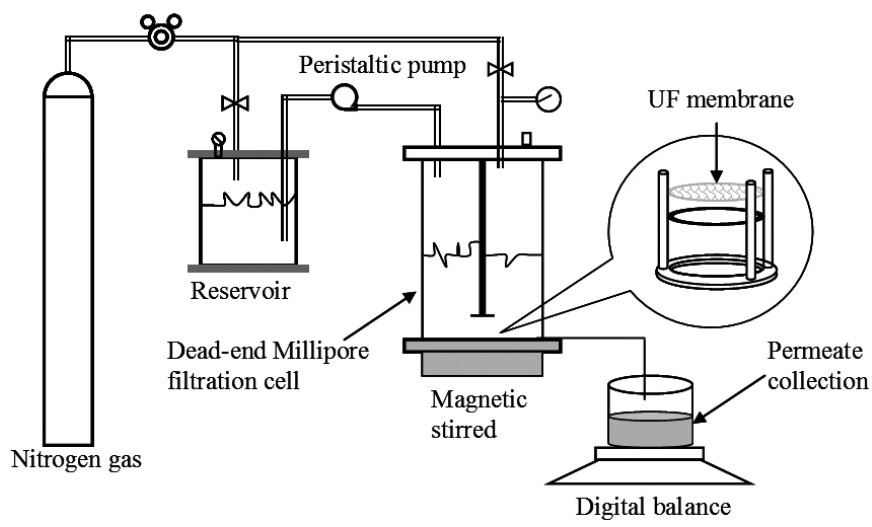

Fig. 1 schematic of dead-end stirred filtration system

HA concentration in permeate was determined by a UV-vis spectrophotometer (Perkin Elmer Instrument, USA) at $254 \mathrm{~nm}$. Permeate was sampled and then recycled into the reservoir together with the retentate. Filtration was repeated two more times. This recycling experiment enabled the separation of concentration polarization effects from fouling effects. The 110 $\mathrm{mL}$ of retentate was then also sampled. In order to determine the extent of irreversible fouling; $1000 \mathrm{~mL}$ of Milli-Q water was filtered through the membrane at the same operating pressure after each experiment. At the end of Milli-Q water filtration, the filtration cell was emptied and the membrane was gently rinsed with pure water to remove the concentration polarization layer contributing to reversible fouling..$^{32,33}$ Care was taken to minimize any disturbance of irreversible NOM fouling layer.

The pure water flux of the membrane was re-evaluated after rinsing for the determination of irreversible foulant resistance. All filtration experiments were conducted at room temperature at about $20^{\circ} \mathrm{C}$.

The rejection coefficient of HA was calculated as (Ec. 2):

$$
R=\frac{C_{o}-C_{p}}{C_{o}} x 100
$$

where $C, C$ are the HA concentration in the feed and permeate respectively. Membrane flux was evaluated following (Ec. 3):

$$
J=\frac{V}{S_{t}}
$$

where $J$ is the membrane flux, $V$ is a permeate volume passed through the membrane with an area of $S$ within time $t$ at operating pressure of $P$.

\section{RESULTS AND DISCUSSION}

Effect of membrane pore size and hydrophilicity

The effect of membrane hydrophilicity on filtration resistance formed during $100 \mathrm{kPa}$ of transmembrane pressure (TMP) and constant $10 \mathrm{Lm}^{-2} \mathrm{~h}^{-1}$ flux, shows that the filtration resistance is the highest for the $10 \mathrm{kDa} P B$ and PL membrane, however in spite to have the same NMWCO (nominal molecular weight cut-off), the hydrophobic membrane (PB) appear to be more prone to fouling than the hydrophilic one (PL) (Fig. 2), This observation are agree with the results reported by Park and $\mathrm{Cho}^{34}$, they report that the transport parameters of NOM in a membrane system depended on the permeability and surface charge.
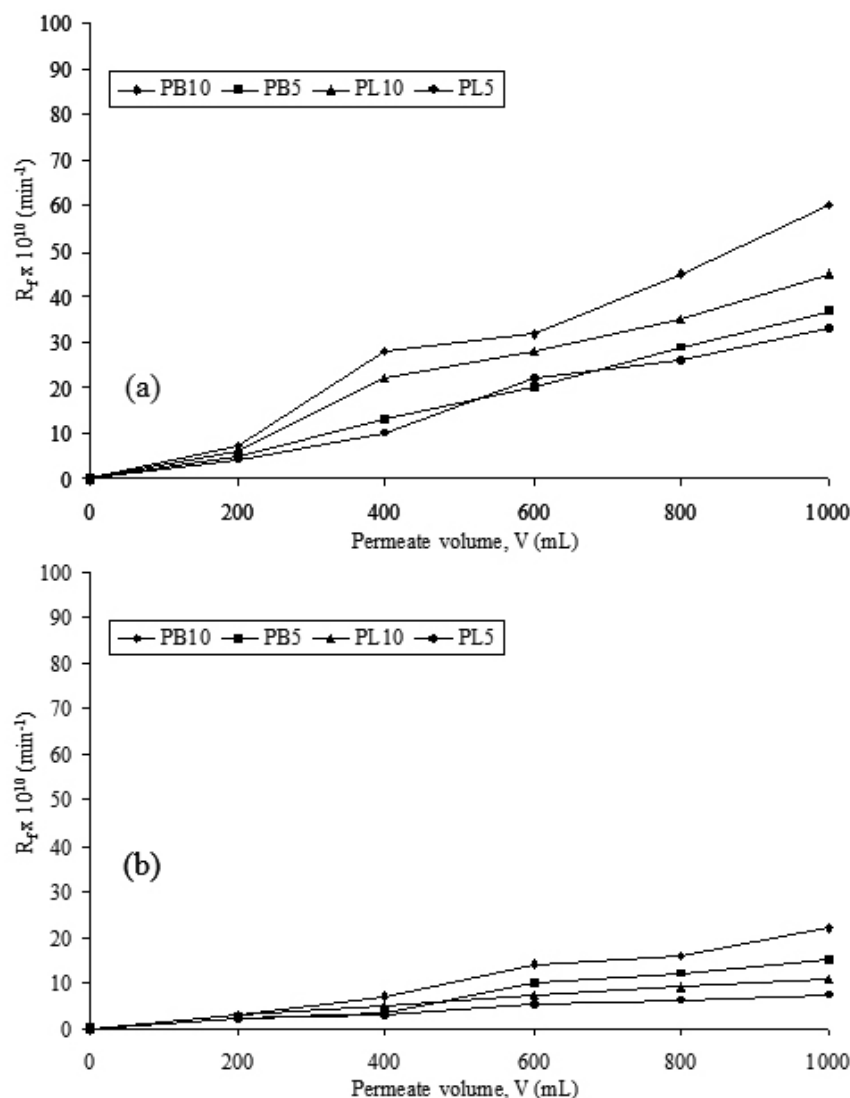

Fig. 2 Effect of membrane surface hydrophilicity on filtration resistance during (a) constant $100 \mathrm{kPa}$ y (b) $10 \mathrm{Lm}^{-2} \mathrm{~h}^{-1}$, at $\mathrm{pH} 7$

The pore size effects on reversible and irreversible fouling percentage with respect to total filtration resistance are shown in Fig. 3. For membrane with $10 \mathrm{kDa}$, the irreversible fouling was dominant; this is due to of HA to be deposited in the internal structure of the membrane. Similar results were observed during constant flux filtrations.

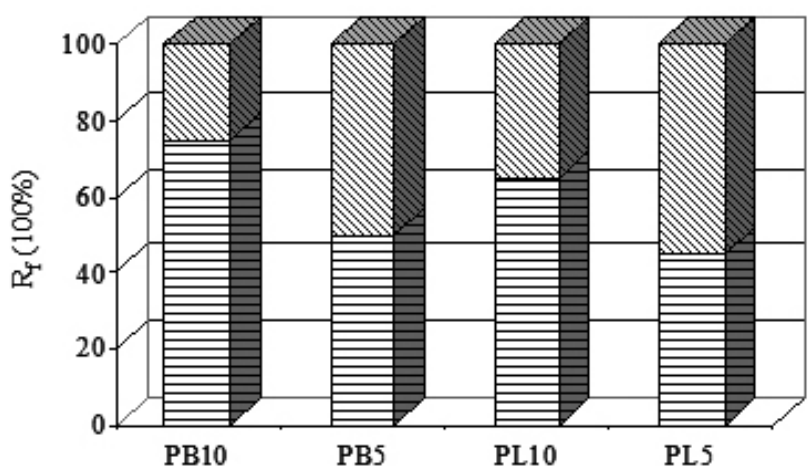

(a) $\quad$ Irreversible fouling $\$$ Reversble fouling 


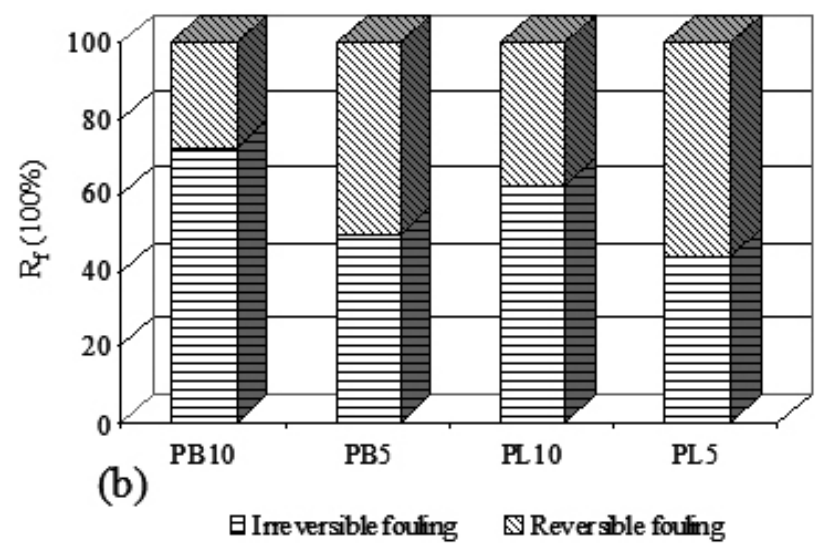

Fig. 3 Effect of membrane pore size on reversible and irreversible fouling NOM during (a) constant $100 \mathrm{kPa}$ presssure, and (b) constant $10 \mathrm{Lm}^{-2} \mathrm{~h}^{-1}$ flux filtrations.

Effect of operating pressure and operating flux

Both at constant operating pressure and flux can be observed two profiles of fouling (Fig. 4).

In a plot of $R_{F}$ against the volume permeate, with the lower fluxes, is not easily to observe the inflection point, this indicates that slow internal fouling is still dominant (Fig. 4b). These behaviors suggest that colloidal fouling is reduced al low constant flux filtration. However, the trends are more consistent when comparing filtration resistance during filtration at $75,100,125$, and $150 \mathrm{kPa}$ (Fig. 4a). By another hand, at higher fluxes, fouling was accelerated because of cake compression.

The effect of operating flux on the percentage of reversible and irreversible fouling with respect to total filtration resistance at the end of constant flux filtration, are shows in Fig. 5. At lower fluxes, the majority of fouling occurred seems to be reversible, while slow internal fouling is dominant.
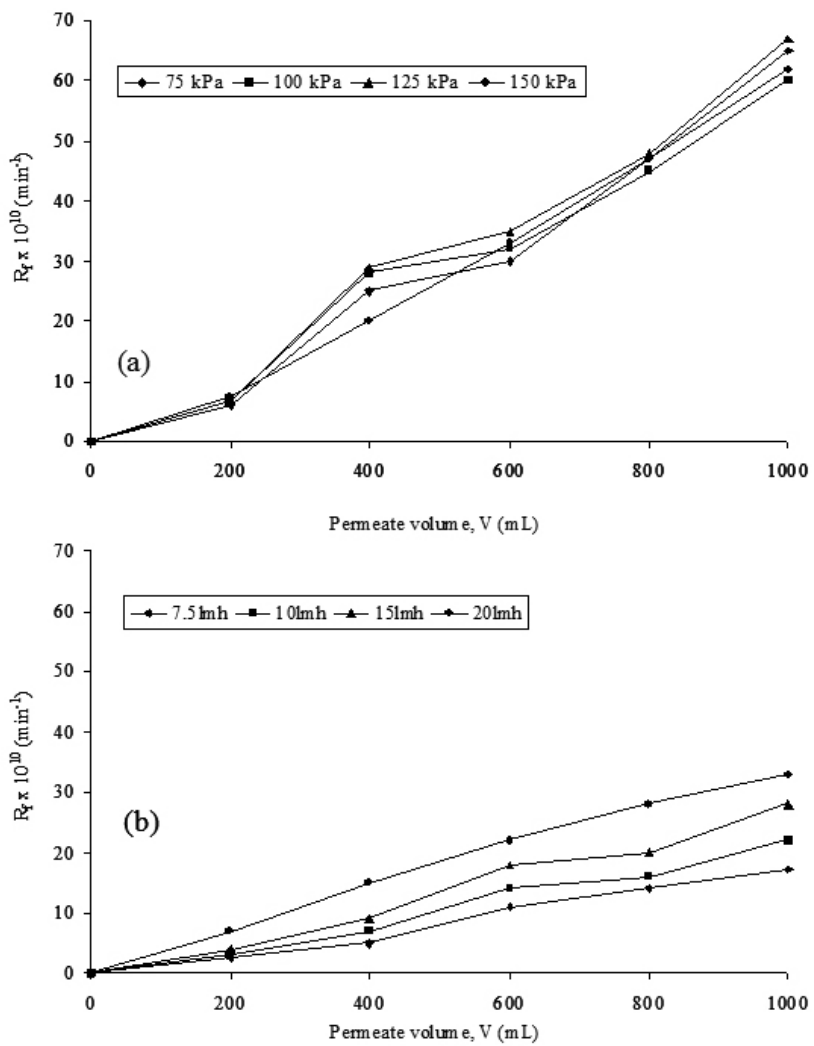

Fig. 4 Effect of (a) operating pressure and (b) operating flux on filtration membrane resistance formed on PB10 membrane.
Analysis of fouling mechanism

When the system is operated at constant pressure, the membranes PB10 reach the highest superficial fouling, while the least fouled membranes were PL5 membranes. It should be noted that the PB series membranes (regenerated cellulose) are hydrophobic, while the PL series are hydrophilic. This same behavior was observed when changing the other operating variables. This relationship of fouling surface shows that there is a fouling model composed of the cake filtration model and the standard pore blocking model. This observation are agree with the results reported by Ho and Zydney ${ }^{29}$ and Chen et al. ${ }^{33}$ they demonstrated that fouling occurs first by pore blockage and then followed by cake formation. However in this study, at large filtration volume, the dominant fouling mechanism is the standard pore blocking model.

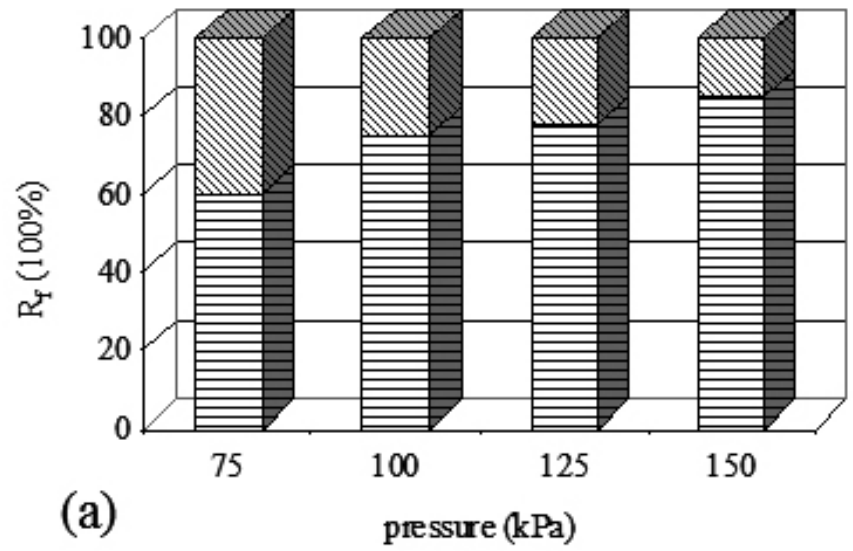

\section{EIrreversible fouling $\mathbb{Q}$ Reversible fouling}

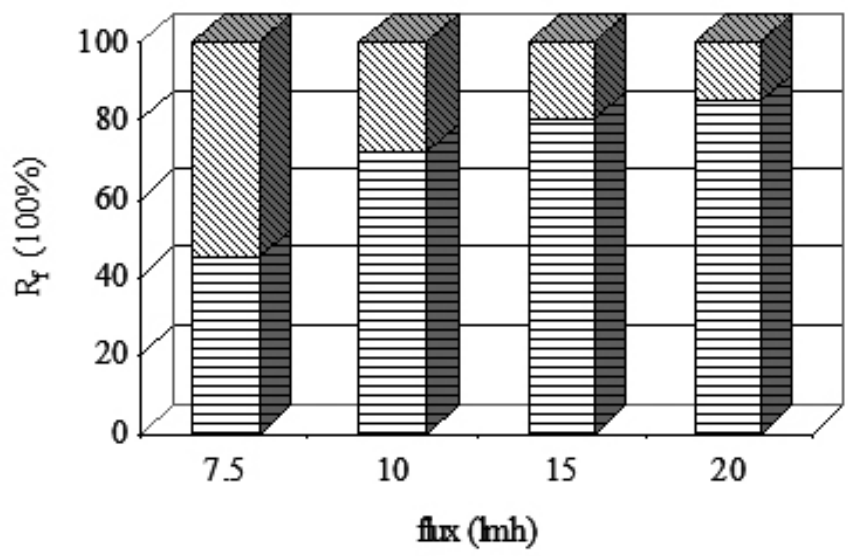

(b)

\section{目Irreversible fouling $\mathbb{Q}$ Reversible fouling}

Fig. 5 Effect of operating flux on reversible and irreversible fouling of NOM on PB10 membranes (a) Pressure (kPa), and (b) flux $\left(\mathrm{Lm}^{-2} \mathrm{~h}^{-1}\right)$

\section{CONCLUSIONS}

High filtration resistance was observed with PB membrane (hydrophobic), and the trends are consistent with cake formation and standard pore blocking model. There are no significant differences for different pressure or constant flux filtration. Also irreversible fouling was dominant on larger pore UF membrane. However in this study, at large filtration volume, the dominant fouling mechanism is the standard pore blocking model. Finally hydrophobic membrane was observed to be more prone to fouling than hydrophilic membrane. 


\section{REFERENCES}

1. A.S. Al-Amoudi, Desalination, 259, 1-10, (2010)

2. Ch. Bellona, J.E. Drewes, P. Xu, G. Amy, Water Research, 38, 2795-2809, (2004).

3. J. Zhou, W. Li, J.S. Gu, H.Y. Yu, Z.Q. Tang, X.W. Wei, Sep. Purif Technol., 71, 233-240, (2010)

4. B.L. Rivas, V.M. Shkinev, T.G. Dzherajan, T.V. Danilova, E.D. Pereira, A. Maureira, J. Chil. Chem. Soc. 55, 53-55, (2010)

5. W.J. Koros, J. Membr. Sci., 85, 218-218, (1993)

6. L. Chee Koh, W.Y. Ahn, M.M. Clark, J. Membr. Sci., 87, 245-256, (1994)

7. M. D. Kennedy, H.K. Chun, V.A. Quintanilla-Yangali, B.G.J. Hiejman, J.C. Shippers, Desalination, 178, 73-83, (2005)

8. M. Taniguchi, J.E. Kilduff, G. Belfort, Environ. Sci. Technol., 281, 472 479, (2006)

9. C. Combe, E. Molis, P. Lucas, R. Riley, M.M. Clark, J. Membr. Sci., 154 73-87, (1999)

10. M. Nyström, A. Pihlajamäki, N. Ehsani, J. Membr. Sci., 87, 245-256, (1994)

11. W. Yuan, A.L. Zydney, Desalination, 122, 63-76, (1999)

12. A.S. Al-Amoudi, A.M. Farooque, Desalination, 178, 261-271, (2005)

13. K.J. Howe, M.M. Clark, Environ. Sci. Technol., 36, 3571-3576, (2002)

14. Ch. Jarusutthirak, S. Mattaraj, R. Jiraratananon, Sep. Purif. Technol., 58, 68-75, (2007)

15. I. Sentana, M.A. De La Rubia, M. Rodriguez, E. Sentana, D. Prats, Sep. Purif. Technol., 68, 305-311, (2009)

16. I. Sutzkover-Gutman, D. Hasson, R. Semiat, Desalination, 261, 218-231, (2010)

17. E. Aoustin, A.I. Schäfer, A.G. Fane, T.D. Waite, Sep. Purif. Technol., 2223, 63-78, (2001)
18. M. Watson, C.D. Hornburg, Desalination, 72, 11-22, (1989)

19. V. Siyanytsya, V. Lochokodan, V. Goncharuk, Desalination, 223, 91-96, (2008)

20. C. García, E. Rogel-Hernandez, G. Rodriguez, F. Wakida, E. Velez, H. Espinoza-Gomez, Desalin. Water Treat., 22, 17-21, (2010)

21. P. Fu, H. Ruiz, K. Thompson, C. Spangenberg, J. $A W W A, \mathbf{8 1}, 41-53$, (1989)

22. J.E. Kilduff, S. Mattaraj, G. Belfort, J. Membr. Sci., 239, 39-53, (2004)

23. C. Jarusutthirak, S. Mattaraj, R. Jiraratananon, J. Membr. Sci., 287, 138145, (2007)

24. S. Hong, M. Elimelech, J. Membr. Sci., 132, 159-181, (1997)

25. C. Garcia, E. Rogel-Hernandez, S.W. Lin, H. Espinoza-Gomez, Desalin. Water Treat., 1, 150-159, (2009)

26. Y. Bessiere, B. Jefferson, E. Goslan, P. Bacchin, Desalination, 249, 182187, (2009)

27. N. Hankins, R. Price, N.A. Debacher, Desalin. Water Treat., 8, 2-16, (2009)

28. Y. Wang, X. Xu, V. Jegatheesan, B. Gao, Desalin. Water Treat., 11, 3237, (2009)

29. C.C. Ho, A.L. Zydney, J. Membr. Sci., 232, 389-399, (2000)

30. R.W. Field, D. Wu, J.A. Howell, B.B. Gupta, J. Membr. Sci., 100, 259272, (1995)

31. A.R. Costa, M.N. de Pinho; M. Elimelech, J. Membr. Sci., 281, 716-725, (2006)

32. Fabris, R.; Lee, E.K.; Chow, C.W.K.; Chen, V.; Drikas, M. J. Membr. Sci., 289, 231-240, (2007)

33. Lee, E.K.; Chen, V.; Fane, A.G. Desalination, 218, 257-270, (2008)

34. N. Park, J. Cho, J. Membr. Sci., 315, 133-140, (2008) 